Original Research Article

\title{
Association of facet orientation and tropism with lumbar disc herniation
}

\author{
Deepak H. R. ${ }^{1}$, Karan Shetty ${ }^{2 *}$, Lakshmi Narayana Reddy G. ${ }^{1}$
}

\author{
${ }^{1}$ Department Orthopaedics, BMCRI, Bangalore, Karnataka, India \\ ${ }^{2}$ Department of Orthopaedics, BIRRD(T) Hospital, Tirupati, Andhra Pradesh, India
}

Received: 06 January 2020

Revised: 20 January 2020

Accepted: 21 January 2020

\author{
*Correspondence: \\ Dr. Karan Shetty, \\ E-mail: eureka.emcc@gmail.com
}

Copyright: $($ ) the author(s), publisher and licensee Medip Academy. This is an open-access article distributed under the terms of the Creative Commons Attribution Non-Commercial License, which permits unrestricted non-commercial use, distribution, and reproduction in any medium, provided the original work is properly cited.

\begin{abstract}
Background: Intervertebral disc herniation is a degenerative lumbar disease and a common pathology of skeletal system. Currently, most experts assume that facet tropism may affect lumbar degenerative diseases. Considering the previous inconsistent findings on the relationship of facet tropism, the present study was aimed to find the association between facet tropism and lumbar disc herniation.

Methods: Patients with low back pain attending the OPD of orthopaedics department, with signs and symptoms of disc herniation were sent for magnetic resonance imaging (MRI). 72 patients with single level disc herniation were included in the study. Facet angles were measured using MRI of $1.5 \mathrm{~T}$ using the method described by Karacan et al. Facet tropism was defined as difference of 100 or more in facet joint angles between right and left sides.

Results: 45 of the 72 cases $(50 \%)$ who presented with lumbar disc herniation (LDH) had tropism while none $(0 \%)$ at the control level did. This association was not statistically significant $(\mathrm{p}=0.983)$. Significant association was found between the side of disc herniation and the distribution of the more coronal or sagittal facing facet $(\mathrm{p}=0.024)$.

Conclusions: Despite the presence of tropism only in the intervertebral segments affected with LDH in our study, the association between tropism and LDH was not statistically significant.
\end{abstract}

Keywords: Facet joint, Facet tropism, Lumbar disc herniation, Orientation of facet joint

\section{INTRODUCTION}

Lumbar disc herniation (LDH) is a common cause of low back pain and lower extremity radicular pain in adults. Two theories are prevalent to explain disc failure mechanical trauma and biochemical changes. The mechanical forces focus on compressional, tensional and axial bending. Rotational forces have also been implicated for disc failure. The degree of rotation at any level of spine is related to anatomy of posterior intervertebral joints- the facet joints. ${ }^{1}$
This led to an increasing interest in the study of asymmetry of facets (tropism) and its potential to alter lumbar spine biomechanics and precipitate early lumbar disc degeneration. ${ }^{2}$ Facet tropism was first defined by Brailsford (1928) as asymmetry between the left and right vertebral facet joint angles, with one more sagittally oriented than the other. ${ }^{3}$ Farfan and Sullivan suggested that coronally oriented facet joint offers little resistance to intervertebral shear force, hence leading to additional torsional stress on the annulus fibrosis. This study gave rise to numerous studies for and against this hypothesis. ${ }^{1}$ 
Owing to the inconsistent results from previous studies to understand whether facet tropism attributes to lumbar disc herniation, in this study, we aim to investigate the relationship between lumbar disc herniation and facet tropism at L3-L4, L4-L5 and L5-S1 intervertebral levels. ${ }^{4-13}$

The main objective of the study is to find the association of facet orientation and tropism with lumbar disc herniation.

\section{METHODS}

This study is a cross-sectional study conducted during the period between November 2018 to November 2019 in the Department of Orthopaedics, Bangalore Medical College and Research Institute, Bangalore. After obtaining institutional ethics committee clearance and written informed consent, patients attending the OPD of orthopaedics department, satisfying the inclusion/ exclusion criteria, were enrolled in the study.

A total 72 patients between the age of 18 and 60 years with single level lumbar disc herniation (L3-L4, L4-L5 or L5-S1) were included in the study considering the same patients as controls (one vertebral joint above \& one vertebral joint below). These patients were treated either operatively or non-operatively. Exclusion criteria included patients with multiple or recurrent disc herniation, associated spondylolisthesis, scoliosis, previous surgery, previous trauma/spinal infection, significant facetal arthropathy, spina bifida or transitional vertebra.

\section{Magnetic resonance imaging}

All patients were subjected to magnetic resonance imaging (MRI) as part of normal course of treatment. MRI was performed with a 1.5T (SIGNA Explorer - GE Healthcare) in all patients with a slice thickness of $4 \mathrm{~mm}$.

T1 axial image sections in which both facet joints were best visualised were considered for angular measurements digitally. All measurements were done using a digital protractor to the nearest tenth of a decimal by a single observer.

Facet angle measurement: A midsagittal line was drawn passing through the centre of the disc and the centre of the base of spinous process, thus dividing the body into two equal halves. Facet lines were drawn on both sides between the anteromedial and posterolateral edges of facets bilaterally. The angle between the midsagittal line and facet lines were the facet angles on either side. Facet tropism was described as the difference between the angle of right and left facet by 10 degrees or more. ${ }^{13}$

Normal adjacent disc level was taken as the control and facet angles were measured at that segment.

\section{Statistical analysis}

Observations were recorded and a master chart was prepared from all observations. The data was analysed using SPSS statistical software of version 20.0. Fischer Exact Test was utilized to determine the statistical significance of categorical variables; $p<0.05$ was considered significant. The statistical analysis for whether the disc herniated more towards the coronal or sagittal side was performed using the test for one proportion.

\section{RESULTS}

In this study, 72 patients with $\mathrm{LDH}$ in one of intervertebral levels (L3-L4, L4-L5, or L5-S1) were investigated and the same patients with one vertebral joint above or below were considered as controls. Among them 56.9\% (41 patients) were male and $43.1 \%$ (31 patients) were female participants. Patients were between the ages 21-57 years with mean and standard deviation $44.46 \pm 12.92$ years.

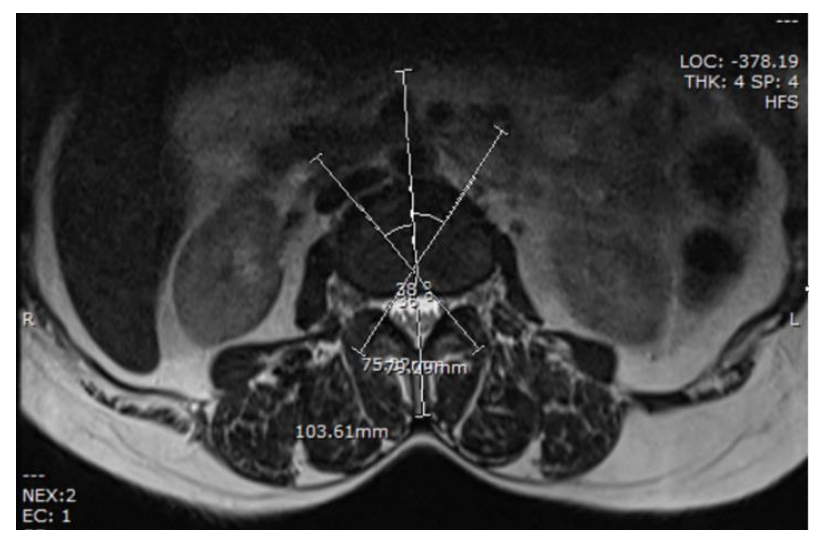

Figure 1: Facet angle at normal level (L3-L4) adjacent to level of disc herniation.

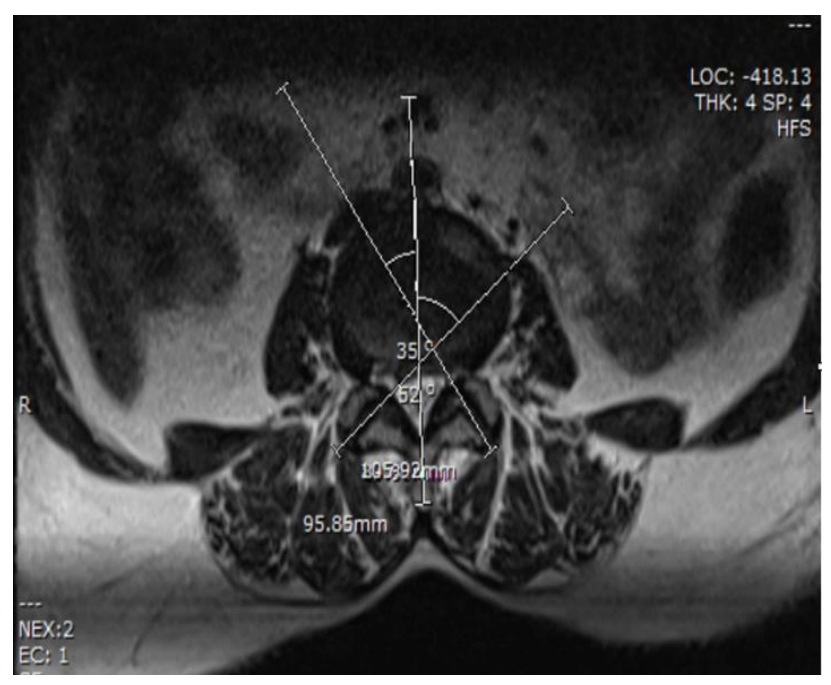

Figure 2: Facet angle showing tropism at level of disc herniation (L4-L5). 
The maximum number of LDH were at L4-L5 ( $\mathrm{n}=53$, $73.6 \%$ ), followed by L5-S1 (14 discs, 19.4\%) while 5 cases of LDH $(6.9 \%)$ were seen at L3-L4. Among these
72 herniated discs, 15 discs herniated towards right, 11 towards left, and 46 towards center.

Table 1: Facet joint orientation at each intervertebral level at the affected and unaffected control segments from cephalad to caudal levels.

\begin{tabular}{|lllllll|}
\hline Level & $\begin{array}{l}\text { Control } \\
\text { Sagittal }\end{array}$ & Coronal & Total & $\begin{array}{l}\text { LDH } \\
\text { Sagittal }\end{array}$ & Coronal & Total \\
\hline & $\mathbf{N}(\%)$ & $\mathbf{N}(\%)$ & & $\mathbf{N}(\%)$ & $\mathbf{N}(\%)$ & \\
\hline $\mathbf{L}_{\mathbf{2}}-\mathbf{L}_{\mathbf{3}}$ & $1(3.4)$ & $0(0.0)$ & 1 & $0(0.0)$ & $0(0.0)$ & 0 \\
\hline $\mathbf{L}_{3}-\mathbf{L}_{\mathbf{4}}$ & $13(44.8)$ & $15(34.9)$ & 28 & $4(13.8)$ & $1(2.3)$ & 5 \\
\hline $\mathbf{L}_{\mathbf{4}-\mathbf{L}_{5}}$ & $5(17.2)$ & $12(27.9)$ & 17 & $23(79.3)$ & $30(69.8)$ & 53 \\
\hline $\mathbf{L}_{5}-\mathbf{S}_{\mathbf{1}}$ & $10(34.5)$ & $16(37.2)$ & 26 & $2(6.9)$ & $12(27.9)$ & 14 \\
\hline Total & $29(100)$ & $43(100)$ & 72 & $29(100)$ & $43(100)$ & 72 \\
\hline
\end{tabular}

Control p-value - 0.425, LDH p-value - 0.024

Table 2: Mean and standard deviations (in degrees) of facet joints at affected and control levels at each intervertebral segment.

\begin{tabular}{|lllll|}
\hline Level & Control $(\mathbf{n}=\mathbf{7 2})$ & LDH $(\mathbf{n = 7 2})$ & T value & P value \\
\hline L2-L3 & $37.00 \pm 0.00$ & 0 & 2.66 & 0.056 \\
\hline L3-L4 & $37.70 \pm 6.45$ & $44.30 \pm 4.95$ & 0.00 & 1.000 \\
\hline L4-L5 & $46.91 \pm 7.66$ & $46.91 \pm 10.68$ & 2.73 & 0.017 \\
\hline L5-S1 & $49.92 \pm 7.68$ & $55.89 \pm 10.45$ & 0 \\
\hline
\end{tabular}

Angles $<45$ degrees suggest sagittal orientation, while angles $>45$ degrees imply coronal orientation.

Table 3: Association between LDH and tropism among cases.

\begin{tabular}{|c|c|c|c|c|}
\hline \multirow{2}{*}{ Herniation } & \multicolumn{2}{|l|}{ Tropism } & \multirow{2}{*}{ Total } & \multirow{2}{*}{ P value } \\
\hline & Absent & Present & & \\
\hline & $\mathbf{N}(\%)$ & $\mathbf{N}(\%)$ & $\mathbf{N}(\%)$ & \\
\hline L3-L4 & $2(40.0)$ & $3(60.0)$ & $5(100)$ & \multirow{4}{*}{0.983} \\
\hline L4-L5 & $20(37.7)$ & $33(62.3)$ & $53(100)$ & \\
\hline L5-S1 & $5(35.7)$ & $9(64.3)$ & $14(100)$ & \\
\hline Total & $27(37.5)$ & $45(62.5)$ & $72(100)$ & \\
\hline
\end{tabular}

Table 4: Overall association between lumbar disc herniation and tropism.

\begin{tabular}{|llll|}
\hline Herniation & $\begin{array}{l}\text { Tropism } \\
\text { Absent }\end{array}$ & Present & Total \\
\hline & $\mathbf{N}(\boldsymbol{\%})$ & $\mathbf{N}(\boldsymbol{\%})$ & $\mathbf{N}(\boldsymbol{\%})$ \\
\hline L2-L3 & $1(100)$ & $0(0.0)$ & $1(100)$ \\
\hline L3-L4 & $31(93.9)$ & $2(6.1)$ & $33(100)$ \\
\hline L4-L5 & $44(62.9)$ & $26(37.1)$ & $70(100)$ \\
\hline L5-S1 & $32(80.0)$ & $8(20.0)$ & $40(100)$ \\
\hline Total & $108(75)$ & $36(25)$ & $144(100)$ \\
\hline
\end{tabular}

Association of facet tropism in cases (LDH) and at all three levels (L3-L4, L4-L5 and L5-S1).

A total $45(62.5 \%)$ of the 72 cases presented with lumbar disc herniation (LDH) had tropism. There was an association between tropism and LDH but it was not statistically significant on Pearson's Chi square analysis. Despite the presence of tropism only in intervertebral segments affected with LDH in our study, this association was not statistically significant $(\mathrm{p}=0.983)$.

Studying patients with herniation in L3-L4 level showed that facet tropism was seen in two of the 5 cases $(20 \%)$. Evaluating tropism in L4-L5 intervertebral level in patients with herniation showed tropism in $33(62.3 \%)$ of the 53 cases in the group. Finally, facet tropism was investigated in L5-S1 intervertebral level, tropism was 
present in $9(64.3 \%)$ out of 14 cases in this level. As there was no asymmetry in facet angles by $>10$ degrees in the control levels, the association was significant at each level by Fischer exact test.

Facet joint tropism occurred on all segments of the lumbar spine, with no significant difference in the incidence of lumbar segments $(\mathrm{p}>0.05)$.

Mean facet joint orientation was measured as described in Table 1. Facet joints of the distal lumbar levels were more coronally oriented than the proximal levels, which were more sagittally oriented.

There was no significant association between LDH and facet tropism $(p=0.983)$. Significant association was found between the side of disc herniation and the distribution of the more coronal or sagittal facing facet $(\mathrm{p}=0.024)$.

\section{DISCUSSION}

The intervertebral disc and both facet joints make a threejoint complex in a motion segment. Each component affects the biomechanics of the other. Lumbar facet joints help in mobility of the spine and restrain the various torsional, and shear forces at each motion segment. More obliquely (coronally) oriented lumbar facets offer little resistance to rotational forces, thus applying greater load on the annulus fibrosus, resulting in lumbar disc herniation. ${ }^{1}$

Numerous studies have been done regarding the relationship between facet joint orientation, tropism and lumbar disc herniation. Van Schaik et al used CT scan to measure facet asymmetry in 100 such cases and noted that with greater degree of asymmetry, there was a greater incidence of unilateral disc protrusion to the side of more coronally oriented facet joint. ${ }^{14}$ Noren et al and Karacan et al in their studies concluded similarly on facet joint asymmetry as a risk factor for degeneration and herniation at lumbar levels. ${ }^{5,15}$ In contrast, other studies suggested no relevance of facet tropism. Hagg et al, Cassidy et al and Vanharanta et al found no clear evidence that facet tropism is strongly associated with lumbar disc herniation. ${ }^{9,8,12}$

We defined facet tropism as the bilateral angle difference $10^{\circ}$ or more. Other studies have defined a similar cut-off to define significant facet orientation asymmetry.

Facet asymmetry was observed at the level of the disc herniation to vary from 35 to $70 \%$ of patients, whereas it was $50 \%$ in the present study. ${ }^{15,16}$ The highest rate of facet tropism was observed at L4-L5 intervertebral level in cases with lumbar disc herniation, followed by L5-S1. This finding was at odds with Ghandhari et al as they observed that incidence of facet tropism at L5-S1 intervertebral level in patient with herniation was $50.8 \%$ $(n=32)$ compared to control group which was $36 \%$ $(n=22)$; although this difference was statistically not significant one. ${ }^{17}$ Similarly, Gao et al in their study, 24 out of 34 patient with lumbar disc herniation at L5-S1 had facet tropism; while in control group, 10 out of 52 patients had facet tropism which was a statistically significant difference. ${ }^{18}$ Tisot et al too observed $47.1 \%$ of patients with LDH in their study to have facet tropism at L5-S1 level. ${ }^{19}$ This variation could possibly be attributed to anthropomorphic differences of the population studied in each study.

There was an increasing obliquity of the facet joints towards a coronal orientation at caudal levels, which was more significant statistically in the levels affected than compared to the same level as normal controls $(\mathrm{p}=0.024)$. This was in agreement with most studies. It is difficult to categorically say that there is an increased occurrence of disc herniation on the side of the more coronally or sagittally oriented facet due to the small number of such cases in our study.

Some earlier studies used CT scans to measure facet angle, while others used MRI as we did. MRI is considered the most useful tool to diagnose lumbar spine pathologies due to its higher contrast resolution.

The presence of tropism only in levels of disc herniation, and its absence in the normal segments in our study suggests an association between tropism and disc herniation. However, this association has been found not to be statistically significant $(\mathrm{p}=0.983)$.

Boden et al and Dinesh et al did not find any significant association between tropism and degeneration of disc. ${ }^{6,16}$

Limitations in the study was to etiology of disc degeneration process and herniation is multifactorial and can be affected by factors like local trauma, lifestyle, race, weight, tobacco use, atherosclerosis, potential anatomical factors and changes happened in the aging process in addition to facet tropism. We also used the normal disc adjacent to the herniated level as the control group. Various authors have done the same in the literature. ${ }^{17}$ It would be ideal if the controls were asymptomatic individuals subjected to MRI.

\section{CONCLUSION}

Considering the previous inconsistent findings on the relationship of facet tropism, the present study aimed to prove that there is a relationship between facet tropism and lumbar disc herniation. Although the facetal obliquity and tropism progressively increased in the caudal intervertebral levels, the association of facet tropism with lumbar disc herniation was not statistically significant. More studies should be performed with a control population to evaluate the efficacy of such measures to prevent the development of disc herniation and symptoms in still asymptomatic patients. 
Funding: No funding sources

Conflict of interest: None declared

Ethical approval: The study was approved by the institutional ethics committee

\section{REFERENCES}

1. Farfan HF, Sullivan JD. The relation of facet orientation to intervertebral disc failure. Can J Surg. 1967;10:179-85.

2. Tulsi RS, Hermanis GM. A study of the angle of inclination and facet curvature of superior lumbar zygapophyseal facets. Spine. 1993;18:1311-7.

3. Brailsford JF. Deformities of the lumbosacral region of the spine. Br J Surg. 1928;16:562-627.

4. Park JB, Chang H, Kim KW, Park SJ. Facet tropism: a comparison between far lateral and posterolateral lumbar disc herniations. Spine. 2001;26:677-79.

5. Noren R, Trafimow J, Andersson GB, Huckman MS. The role of facet joint tropism and facet angle in disc degeneration. Spine. 1991;16:530-2.

6. Boden SD, Riew KD, Yamaguchi K, Branch TP, Schellinger D, Wiesel SW. Orientation of the lumbar facet joints: association with degenerative disc disease. J Bone Jt Surg Am. 1996;78:403-11.

7. Adams MA, Hutton WC. The relevance of torsion to the mechanical derangement of the lumbar spine. Spine. 1981;6:241-8.

8. Cassidy JD, Loback D, Yong-Hing K, Tchang S. Lumbar facet joint asymmetry. Intervertebral disc herniation. Spine. 1992;17:570-4.

9. Hagg O, Wallner A. Facet joint asymmetry and protrusion of intervertebral disc. Spine. 1990;15:356-9.

10. Ishihara $H$, Matsui $H$, Osada $R$, Ohshima $H$, Tsuji $\mathrm{H}$. Facet joint asymmetry as a radiologic feature of lumbar intervertebral disc herniation in children and adolescents. Spine. 1997;22:2001-4.
11. Ko HY, Park BK. Facet tropism in lumbar motion segments and its significance in disc herniation. Arch Phys Med Rehabil. 1997;78:1211-4.

12. Vanharanta H, Floyd T, Ohnmeiss D. The relationship of facet tropism to degenerative disc disease. Spine. 1993;18:1000-5.

13. Chadha M, Sharma G. Association of facet tropism with lumbar disc herniation. Eur Spine J. 2012;22(5):1045-52.

14. Van Schaik JPJ, Verbiest H, van Schanik FDJ. The orientation and shape of the lower lumbar facet joints: a computed tomographic study of their variation in 100 patients with low back pain and a discussion of their possible clinical implications. In: MJ Donovan Post (ed) Computed tomography of the Spine. Baltimore: Williams Wilkins; 1984: 495505.

15. Karacan I, Aydin T, Sahin Z, Cidem M, Koyuncu H, Aktas I, et al. Facet angles in lumbar disc herniation: their relation to anthropometric features. Spine. 2004;29:1132-6.

16. Dinesh K. The role of facet tropism in lumbar intervertebral disc prolapse. Int J Ortho Sci. 2017;3(2):219-21.

17. Ghandhari H, Ameri E, Hasani H. Is facet tropism associated with increased risk of disc herniation in the lumbar spine? Asian Spine J. 2018;12:428.

18. Gao T, Lai Q, Zhou S. Correlation between facet tropism and lumbar degenerative disease: a retrospective analysis. BMC Musculoskeletal Disord. 2017; 18:483

19. Tisot RA, Vieira JDS, Collares DDS. Influence of facet tropism on the location of lumbar disc herniation. Coluna/Columna. 2018;17:23-6.

Cite this article as: Deepak HR, Shetty K, Reddy LNG. Association of facet orientation and tropism with lumbar disc herniation. Int J Res Orthop 2020;6:296-300. 